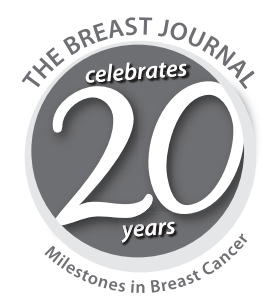

\title{
Managing Anxiety and Depression During Treatment
}

\author{
David Spiegel," and Michelle B. Riba ${ }^{\dagger}$ \\ *Department of Psychiatry, Stanford School of Medicine, Stanford, California; ${ }^{\dagger}$ Department of \\ Psychiatry, University of Michigan, Ann Arbor, Michigan
}

- Abstract: Here, we review the prevalence and treatment of anxiety and depression among patients with breast cancer. Cancer-related symptoms include similarities to responses to traumatic stress. Well-developed screening devices for identifying and tracking psychiatric comorbidity are discussed. Basic principles of psychopharmacology, and individual and group psychotherapy are presented. Finally, effects of effective treatment of anxiety and depression on quality of life and overall survival are reviewed.

Key Words: breast cancer, anxiety, depression, psychopharmacology, psychotherapy, outcome, survival

A nxiety and depression are the most common psychiatric disorders, and may be induced or exacerbated by the diagnosis and treatment of breast cancer. These comorbid illnesses affect quality of life, adherence to treatment, social support, and survival time. Effective coping with the disease involves dealing with its direct and indirect effects. Facing breast cancer and its consequences requires acknowledging and managing strong but inevitable emotions that can interfere with medical care (1), family and vocational engagement, sleep, diet, and exercise (2).

A high prevalence of psychiatric and psychological problems affect patients and families before, during, and after cancer care and treatment.

While many would like to maintain a positive view of the diagnosis and treatment for cancer, for many a diagnosis of breast cancer constitutes a trauma analogous to experiencing a physical assault, accident, or natural disaster. Many patients remember the date and time they received their cancer diagnosis, exactly where it was discussed, who said it, the specific words that were used, and how they felt. These life-altering, life-changing moments are, psychologically riveting. In the initial period of diagnosis and treatment, the term acute stress disorder or posttraumatic stress disorder

Address correspondence and reprint requests to: David Spiegel, MD, Professor of Psychiatry \& Behavioral Sciences, Jack, Lulu \& Sam Willson Professor, Department of Psychiatry, Stanford School of Medicine, Room 2325, 401 Quarry Rd., Stanford, CA 93405, USA, or e-mail: dspiegel@ stanford.edu

DOI: $10.1111 /$ tbj.12355

(C) 2014 Wiley Periodicals, Inc., 1075-122X/15

The Breast Journal, Volume 21 Number 1, 2015 97-103
(PTSD) may best describe the psychological problems that occur (3). In one study of breast cancer patients after treatment, $5-10 \%$ met diagnostic criteria for PTSD, (4) and the symptoms changed little over the ensuing year (5). Such patients experience intrusive thoughts, disbelief, avoidance, inability to sleep, fears, and physiological hyperarousal. Their lives change suddenly from the mundane routine of work or family activities, to a string of doctors' appointments, receiving life-altering news and data in technical language, making appointments for surgery, blood draws, chemotherapy, and radiotherapy.

As patients move through the stages of cancer care, the trauma response may persist from acute stress to a more chronic PTSD (6-8). Even cessation of acute treatment can be fraught with anxiety about recurrence and withdrawal of active medical support. Yet many patients and their families also experience what has been called posttraumatic growth, an altered perspective on what matters in life that comes from facing and dealing with major life stressors (9). This ability to come to terms with the implications of the disease and enhance relating to others, appreciation of life, and spiritual change occurs in a substantial proportion of cancer patients $(10,11)$ and in some cases predicts better long-term adjustment (12).

\section{SCREENING FOR PSYCHOLOGICAL PROBLEMS}

In 1997 the National Comprehensive Cancer Network published the Distress Management Guidelines, 
which is updated regularly as a tool for oncology clinicians to develop a differential diagnosis of distress, including common psychiatric disorders and psychosocial and spiritual problems (nccn.org). More recently, the NIH has developed a series of brief reliable and valid measures, the Patient-Reported Outcomes Measurement System $(13,14)$.

\section{SLEEP}

Eighty percent of patients undergoing chemotherapy and more than two-thirds of women with metastatic breast cancer experience poor sleep $(15,16)$, which is associated with numerous negative physical and mental health outcomes $(17,18)$. Sleep duration and disruption have been associated with all-cause mortality $(19,20)$. The precise relationship, however, is likely complex because some studies have shown that short sleep duration is implicated in earlier mortality (21), whereas others suggest the relationship is quadratic, in which both shorter and longer sleep duration than normal are predictive of shorter survival (22).

Although precipitating factors for the development of sleep disruption include stress associated with the diagnosis of cancer and its treatment $(23,24)$ and cytotoxic chemotherapy and its side effects (25), the mechanism behind the development of sleep disruption and how it might affect survival is not well understood (18). Prior studies found relationships between tumor characteristics and spread, receptor status, and treatment with survival in metastatic breast cancer (26). Other studies have shown that circadian dysregulation measured by flattened cortisol rhythms (27) and depression (28) are independent prognostic factors for survival in metastatic breast cancer. We have recently found that better sleep efficiency and less sleep disruption as measured by wrist actigraphy are significant independent prognostic factors of overall survival time in women with advanced breast cancer (29).

\section{TREATMENT INTERVENTIONS}

\section{Psychotropic Medication}

Antidepressants It is clear that, as is the case with major depression in general, depression that arises in the context of cancer is responsive to antidepressant treatment (30). Antidepressants decrease depressive symptoms, improve functional capacity, reduce cachexia, ameliorate some menopausal symptoms, and reduce pain (31). Even patients with advanced disease benefit, despite not having the full range of depressive symptoms (32). Selective serotonin reuptake inhibitors may improve depressive symptoms without reducing fatigue (33).

\section{Antianxiety Agents}

Antidepressants have antianxiety properties as well and can be utilized effectively for the common problem of mixed anxiety and depression. Benzodiazepines can provide immediate short-term relief of anxiety symptoms, but generally are not a good strategy for long-term treatment, in part because of the likelihood of habituation and a tendency to produce dependence. Withdrawal from high doses can be a serious medical problem, including risk of seizures.

\section{Psychosocial Interventions}

The efficacy of psychosocial treatments for depression and anxiety in medically ill patients, particularly brief psychodynamic, educational, supportive, and interpersonal therapies, hypnosis, and behavioral and cognitive-behavioral methods, has been established in numerous outcome studies (34-38).

\section{Cognitive-Behavioral Therapy}

The cognitive-behavioral approach (39) is built on the assumption that previous social learning, developmental history, and significant experiences lead people to form a dysfunctional set of meanings and assumptions, or cognitive schemas, about themselves, the world, and their future. These schemas organize perception and govern and evaluate behavior (40). When specific schemas are activated, they directly influence the content of a person's perceptions, interpretations, associations, and memories, often in a way that exacerbates anxiety and depression. The cognitive behavioral therapy (CBT) therapist seeks to identify maladaptive cognitions, turn them into testable hypotheses, and submit them to open examination, so the patient can then reject, modify, or retain these thoughts based on the evidence. More adaptive cognitions and behaviors are similarly evaluated. In the early sessions, the goal of CBT is to establish a therapeutic relationship, identify primary problems, produce symptom relief, and educate the patient 
about the role of thoughts, images, and beliefs on emotions and behavior. Together, the therapist and patient decide on the treatment goal, a plan for subsequent therapy sessions, and homework assignments intended to consolidate the therapy and direct structured practice. The initial homework often requires the patient to identify and record maladaptive cognitions (e.g., automatic thoughts). As therapy continues, verbal techniques are employed to trigger automatic thoughts and associated assumptions and reveal core beliefs or schemas. In an environment of collaborative empiricism, the patient learns to identify and evaluate, logically and empirically, the usefulness of systematic biases, cognitive distortions and dysfunctional assumptions, and thoughts, images, and beliefs that underlie emotional distress. The therapist helps the patient challenge cognitive distortions such as overgeneralization, catastrophizing, "should" statements, magnification, minimization, dichotomous thinking, and the fallacies of excessive control, worry, fairness, and attachment. Cognitive restructuring techniques and guided discovery help the patient to choose more adaptive cognitions and behaviors. Cognitive techniques used in CBT include thoughtstopping, self-instruction, distraction, direct disputation, labeling distortions, and the development of replacement imagery. Behavioral techniques including activity scheduling, relaxation training, social skills training, mastery and pleasure ratings, assertiveness training, bibliotherapy, homework, behavioral rehearsal, and in vivo exposure are also employed

\section{Group Psychotherapy}

Group intervention in a variety of forms has become an increasingly popular, effective, and efficient means of providing psychosocial support for breast cancer patients $(41,42)$. Groups of different types include psychodynamic, existential, educational, supportive-expressive, and cognitive-behavioral models (41). Although some cancer patients are initially disinclined to join a support group, most are also reluctant to undertake other aspects of cancer treatment as well. Many breast cancer patients, especially those with anxiety and depressive symptoms, need and can benefit from support in dealing with diagnosis and treatment, changes wrought by disease, social isolation, and existential issues.

Common elements of group psychotherapeutic intervention include the following (42):
Social Support Psychotherapy, especially in groups, can provide a new social network cemented by the common bond of facing similar problems. At a time when the illness makes a person feel removed from the flow of life, when many others withdraw out of awkwardness or fear, group psychotherapeutic support provides a new and meaningful social connection. Furthermore, members find that the process of offering help to others enhances their own sense of mastery of the role of "patient" and increases their self-esteem.

Emotional Expression The expression of emotion is important in reducing social isolation and reducing anxiety and depressive symptoms $(43,44)$. Patients often have the mistaken belief that they are controlling the psychological and even physical impact of the disease by suppressing their emotional reaction to it. This attitude is often reinforced by friends and family who are made anxious by exposure to a patient's appropriate fear or sadness. Medical professionals may perceive a patient's sadness as an indication of dissatisfaction with treatment or loss of hope.

Detoxifying Dying Facing rather than avoiding existential concerns such as dying and death, which could be considered likely to exacerbate depression, actually helps to reduce it. This encourages patients to face what they most fear and find some aspect of it they can do something about (e.g., control the process of dying when death is unavoidable). This helps patients to feel more active and less helpless, even in the face of dying (42). Death anxiety is intensified by isolation, in part because patients often conceptualize death in terms of separation from loved ones. This can be powerfully addressed by directly confronting such concerns in a supportive psychotherapeutic setting (45). Even the process of grieving for others who have died of the same condition constitutes a deeply personal experience of the depth of loss that will be experienced by others after one's own death.

Reorganizing Life Priorities and Living in the Present The acceptance of the possibility of illness shortening life carries with it an opportunity for reevaluating life priorities (46). This can help patients take control of those aspects of their lives they can influence, while relinquishing those they cannot (47).

Enhancing Family Support Psychotherapeutic interventions can also be quite helpful to families in 
improving communication, identifying needs, increasing role flexibility, and adjusting to new medical social, vocational, and financial realities (48).

Improving Communication with Physicians Support groups can be quite useful in practicing better communication with physicians and other health care professionals $(49,50)$.

\section{SYMPTOM CONTROL}

Many group and individual psychotherapy programs teach specific coping skills designed to help patients reduce cancer-related symptoms such as anxiety, anticipatory nausea and vomiting, and pain, which can exacerbate both anxiety and depression. Techniques used include specific self-regulation skills such as self-hypnosis, meditation, biofeedback, and progressive muscle relaxation.

Hypnosis is widely used for pain and anxiety control in cancer to attenuate the experience of pain and suffering (51). Instruction in self-hypnosis provides an effective means of reducing pain and anxiety $(52,53)$. Hypnosis is an altered state of consciousness, consisting of heightened absorption in focal attention, dissociation of peripheral awareness, and enhanced responsiveness to social cues (49). It is effective in controlling somatic symptoms such as pain and anxiety. Patients with the requisite hypnotic capacity can be taught self-hypnosis exercises to effectively reduce cancer pain $(49,52,53)$, and to facilitate participation in medical procedures (54).

\section{Mindfulness Training}

Mindfulness-based stress reduction enhances the ability to live in the moment and to tolerate stresses as real but transient phenomena, while more comfortably relating to one's body, often employing gentle yoga exercises as well (55). Such techniques have been used effectively with cancer patients. Other studies have shown that a combination of mindfulness with more traditional group therapy produces reductions in intrusive thinking and other posttraumatic stress symptoms (56), as well as reduced depression, fear of recurrence, and higher energy (57) among women with breast cancer. A recent study of mindfulness for primary breast cancer patients demonstrated greater reductions in stress symptoms than in an intervention involving emotional expression or a control group, and showed that both treatment conditions resulted in normalization of diurnal cortisol levels.

Electronic Technology-Based Interventions Technology-assisted interventions are highly effective and offer great possibilities for dissemination. A peer-modeling videotape shown to patients shortly after diagnosis induced increases in vitality and posttraumatic growth and decreases in depression and intrusive thoughts (58). A combination of home visiting and telephone intervention resulted in reduced pain (59). Computerbased patient support tools provide information, decision support, and interaction with other patients and yield not only increments in knowledge but also better doctor-patient interactions and enhanced social support (60). Support groups have been adapted to the Internet with good effect. For example, onlinemediated social support for cancer-related fatigue have proven beneficial (61).

\section{OUTCOME}

Randomized clinical trials have demonstrated the benefit of group therapy for breast cancer patients $(45,62-64)$, with notable reductions in pain $(52,53)$ and emotional distress $(44,65)$.

\section{IMPLICATIONS FOR OVERALL SURVIVAL}

Psychotherapeutic intervention may affect survival time as well as quality of life $(66-70)$. A year of supportive-expressive group psychotherapy resulted in a significant 18 -month increase in survival time in metastatic breast cancer patients (66). A randomized replication trial of supportive-expressive group psychotherapy among 125 women with metastatic breast cancer demonstrated positive effects on mood (44) but no overall survival advantage (71), although there was a significant interaction with tumor type, such that those women with estrogen receptor-negative tumors who had been randomized to the group condition lived significantly longer than estrogen receptor-negative controls. A randomized educational group intervention trial among 227 women with primary breast cancer demonstrated that group support resulted in significantly lower rates of relapse and mortality at 11-year follow-up.

One large multicenter trial that utilized supportiveexpressive group psychotherapy with metastatic breast cancer patients showed reduced distress and pain but 
no survival advantage (72). However, the treatment arm in this study was more depressed than the controls at the beginning of the study, which indicates risk for shorter survival prior to intervention (28). Taken together, these studies suggest that psychosocial effects on survival time are more pronounced when medical treatments have become less effective (64). No study has found that psychotherapy shortens survival. The potential benefit of psychotherapeutic support on cancer progression remains an open research question, but receives further support from recent evidence that being married is associated with a $12-33 \%$ improvement in overall survival in ten kinds of cancer, including breast (73). This study involved analysis of SEER data from 2004 to 2008 involving 734,889 cancer patients with lung, colorectal, breast, pancreatic, prostate, liver/intrahepatic bile duct, non-Hodgkin lymphoma, head/neck, ovarian, or esophageal cancer. Being married was associated with better outcome among all ten cancer types, independent of demographics, stage and treatment. Thus, social support has a tangible effect on disease progression and survival time.

\section{SURVIVORSHIP}

Survivorship is an increasingly important aspect of comprehensive cancer care as cancer survival improves. Supportive services and surveillance for anxiety and depression should continue after active oncologic treatment is completed (74). Domains of intervention include surveillance for recurrence and late effects of treatment, genetic issues, overall health maintenance, attention to psychiatric, social, behavioral, and financial problems, and other factors that affect mood and other aspects of quality of life. This includes attention to physical activity, which until recently has been a neglected area for breast cancer survivors. There is growing evidence that moderate to vigorous physical exercise improves health-related quality of life (75) and reduces depression (76) among cancer patients. Many survivorship programs are helping patients and their families deal with the aftermath of treatment through formal survivorship clinics, classes, group support, nutritional consultation, social services, and psychiatric support.

\section{CONCLUSION}

Anxiety and depression are frequent but treatable problems that can complicate the lives of breast cancer patients and their families. Frequent assessment and early intervention can improve quality of life, adherence to treatment, and overall outcome.

\section{REFERENCES}

1. Grube M. Compliance and coping potential of cancer patients treated in liaison-consultation psychiatry. Int J Psychiatry Med 2006;36:211-29.

2. Spiegel D. A 43-year-old woman coping with cancer. JAMA 1999;282:371-8.

3. APA. Diagnostic and Statistical Manual of Mental Disorders, 5th edn (DSM-5). Washington, DC: American Psychiatric Assn, 2013.

4. Jacobsen PB, Widows MR, Hann DM, Andrykowski MA, Kronish LE, Fields KK. Posttraumatic stress disorder symptoms following bone marrow transplantation for breast cancer. Psychosom Med 1998;60:366-71.

5. Andrykowski MA, Cordova MJ, McGrath PC, Sloan DA, Kenady DE. Stability and change in posttraumatic stress disorder symptoms following breast cancer treatment: a 1-year follow-up. Psychooncology 2000;9:69-78.

6. Green BL, Rowland JH, Krupnick JL, et al. Prevalence of posttraumatic stress disorder (PTSD) in women with breast cancer. Psychometrics 1998;32:102-11.

7. Koopman C, Butler LD, Classen C, et al. Traumatic stress symptoms among women with recently diagnosed primary breast cancer. J Trauma Stress 2002;15:277-87.

8. Cordova MJ, Andrykowski MA, Kenady DE, McGrath PC, Sloan DA, Redd WH. Frequency and correlates of PTSD-like symptoms following treatment for cancer. J Consult Clin Psychol 1995;63:981-6

9. Tedeschi RG, Calhoun LG. The Posttraumatic Growth Inventory: measuring the positive legacy of trauma. J Traum Stress 1996;9:455-71.

10. Cordova MJ, Cunningham LL, Carlson CR, Andrykowski MA. Social constraints, cognitive processing, and adjustment to breast cancer. J Consult Clin Psychol 2001;69:706-11.

11. Cordova MJ, Cunningham LL, Carlson CR, Andrykowski MA. Posttraumatic growth following breast cancer: a controlled comparison study. Health Psychol 2001;20:176-85.

12. Carver CS, Antoni MH. Finding benefit in breast cancer during the year after diagnosis predicts better adjustment 5 to 8 years after diagnosis. Health Psychol 2004;23:595-8.

13. O'Hara R, Thompson JM, Kraemer HC, et al. Which Alzheimer patients are at risk for rapid cognitive decline? J Geriatr Psychiatry Neurol 2002;15:233-8.

14. Mauricio M, O’Hara R, Yesavage JA, et al. A longitudinal study of apolipoprotein-E genotype and depressive symptoms in community-dwelling older adults. Am J Geriatr Psychiatry 2000;8:196-200.

15. Palesh OG, Roscoe JA, Mustian KM, et al. Prevalence, demographics, and psychological associations of sleep disruption in patients with cancer: University of Rochester Cancer Center-Community Clinical Oncology Program. J Clin Oncol 2010;28:292-8.

16. Palesh OG, Collie K, Batiuchok D, et al. A longitudinal study of depression, pain, and stress as predictors of sleep disturbance among women with metastatic breast cancer. Biol Psychol 2007;75:37-44.

17. Harrington CB, Hansen JA, Moskowitz M, Todd BL, Feuerstein M. It's not over when it's over: long-term symptoms in cancer survivors-a systematic review. Int J Psychiatry Med 2010; 40:163-81. 
18. Palesh O, Peppone L, Innominato PF, et al. Prevalence, putative mechanisms, and current management of sleep problems during chemotherapy for cancer. Nat Sci Sleep 2012;4:151-62.

19. Cohen-Mansfield J, Perach R. Sleep duration, nap habits, and mortality in older persons. Sleep 2012;35:1003-9.

20. Cappuccio FP, D’Elia L, Strazzullo P, Miller MA. Sleep duration and all-cause mortality: a systematic review and meta-analysis of prospective studies. Sleep 2010;33:585-92.

21. Kripke DF, Garfinkel L, Wingard DL, Klauber MR, Marler MR. Mortality associated with sleep duration and insomnia. Arch Gen Psychiatry 2002;59:131-6.

22. Gallicchio L, Kalesan B. Sleep duration and mortality: a systematic review and meta-analysis. J Sleep Res 2009;18:148-58.

23. Costanzo ES, Stawski RS, Ryff CD, Coe CL, Almeida DM. Cancer survivors' responses to daily stressors: implications for quality of life. Health Psychol 2012;31:360-70.

24. Spiegel D. Mind matters in cancer survival. Psychooncology 2012;21:588-93.

25. Cleeland CS, Allen JD, Roberts SA, et al. Reducing the toxicity of cancer therapy: recognizing needs, taking action. Nat Rev Clin Oncol 2012;9:471-8.

26. Nicolini A, Giardino R, Carpi A, et al. Metastatic breast cancer: an updating. Biomed Pharmacother 2006;60:548-56.

27. Sephton SE, Sapolsky RM, Kraemer HC, Spiegel D. Diurnal cortisol rhythm as a predictor of breast cancer survival. I Natl Cancer Inst 2000;92:994-1000.

28. Giese-Davis J, Collie K, Rancourt KM, Neri E, Kraemer HC, Spiegel D. Decrease in depression symptoms is associated with longer survival in patients with metastatic breast cancer: a secondary analysis. J Clin Oncol 2011;29:413-20.

29. Palesh O, Aldridge-Gerry A, Zeitzer JM, et al. Actigraphy-measured sleep disruption as a predictor of survival among women with advanced breast cancer. Sleep 2014;37:837-42.

30. Pezzella G, Moslinger-Gehmayr R, Contu A. Treatment of depression in patients with breast cancer: a comparison between paroxetine and amitriptyline. Breast Cancer Res Treat 2001;70: $1-10$.

31. Berney A, Stiefel F, Mazzocato C, Buclin T. Psychopharmacology in supportive care of cancer: a review for the clinician. III. Antidepressants. Support Care Cancer 2000;8:278-86.

32. Fisch MJ, Loehrer PJ, Kristeller J, et al. Fluoxetine versus placebo in advanced cancer outpatients: a double-blinded trial of the Hoosier Oncology Group. J Clin Oncol 2003;21:1937-43.

33. Morrow GR, Hickok JT, Roscoe JA, et al. Differential effects of paroxetine on fatigue and depression: a randomized, double-blind trial from the University of Rochester Cancer Center Community Clinical Oncology Program. J Clin Oncol 2003;21:4635-41.

34. Aziz NM, Rowland JH. Trends and advances in cancer survivorship research: challenge and opportunity. Semin Radiat Oncol 2003;13:248-66.

35. Compas BE, Haaga DA, Keefe FJ, Leitenberg H, Williams DA. Sampling of empirically supported psychological treatments from health psychology: smoking, chronic pain, cancer, and bulimia nervosa. J Consulting Clin Psychol 1998;66:89-112.

36. Barsevick AM, Sweeney C, Haney E, Chung E. A systematic qualitative analysis of psychoeducational interventions for depression in patients with cancer. Oncol Nurs Forum 2002;29:73-84; quiz 5-7.

37. Devine EC, Westlake SK. The effects of psychoeducational care provided to adults with cancer: meta-analysis of 116 studies. Oncol Nurs Forum 1995;22:1369-81.

38. Grunfeld E. Looking beyond survival: how are we looking at survivorship? J Clin Oncol 2006;24:5166-9.
39. Beck JS. Cognitive Therapy: Basics and Beyond. New York: Guliford Press, 1995.

40. Hollon SD, Shelton RC, Davis DD. Cognitive therapy for depression: conceptual issues and clinical efficacy. J Consult Clin Psychol 1993;61:270-5.

41. Yalom I. Theory and Practice of Group Psychotherapy. New York: Basic, 1995.

42. Spiegel D, Classen C. Group Therapy for Cancer Patients: A Research-Based Handbook of Psychosocial Care. New York: Basic Books, 2000.

43. Giese-Davis J, Koopman C, Butler LD, et al. Change in emotion-regulation strategy for women with metastatic breast cancer following supportive-expressive group therapy. J Consult Clin Psychol 2002;70:916-25.

44. Classen C, Butler LD, Koopman C, et al. Supportive-expressive group therapy and distress in patients with metastatic breast cancer: a randomized clinical intervention trial. Arch Gen Psychiatry 2001;58:494-501.

45. Yalom ID. Existential Psychotherapy. New York: Basic Books, 1980.

46. Kinsinger DP, Penedo FJ, Antoni MH, Dahn JR, Lechner S, Schneiderman N. Psychosocial and sociodemographic correlates of benefit-finding in men treated for localized prostate cancer. Psychooncology 2006;15:954-61.

47. Andrykowski MA, Beacham AO, Schmidt JE, Harper FW. Application of the theory of planned behavior to understand intentions to engage in physical and psychosocial health behaviors after cancer diagnosis. Psychooncology 2006;15:759-71.

48. Wellisch DK. Families and cancer. Psychooncology 1998;7:1-2.

49. Spiegel D. Tranceformations: hypnosis in brain and body. Depression and Anxiety 2013;30:342-52.

50. Fallowfield LJ, Jenkins VA, Beveridge HA. Truth may hurt but deceit hurts more: communication in palliative care. Palliat Med 2002;16:297-303.

51. Spiegel H, Spiegel D. Trance and Treatment: Clinical Uses of Hypnosis. Washington, DC: American Psychiatric Press, 1987.

52. Spiegel D, Bloom JR. Group therapy and hypnosis reduce metastatic breast carcinoma pain. Psychosom Med 1983;45: 333-9.

53. Butler LD, Koopman C, Neri E, et al. Effects of supportive-expressive group therapy on pain in women with metastatic breast cancer. Health Psychol 2009;28:579-87.

54. Lang E, Benotsch E, Fink L, et al. Adjunctive non-pharmacological analgesia for invasive medical procedures: a randomised trial. Lancet 2000;355:1486-90.

55. Kabat Zinn J, Massion AO, Kristeller J, et al. Effectiveness of a meditation-based stress reduction program in the treatment of anxiety disorders. Am J Psychiatry 1992;149:936-43.

56. Levine EG, Eckhardt J, Targ E. Change in post-traumatic stress symptoms following psychosocial treatment for breast cancer. Psychooncology 2005;14:618-35.

57. Lengacher CA, Johnson-Mallard V, Post-White J, et al. Randomized controlled trial of mindfulness-based stress reduction (MBSR) for survivors of breast cancer. Psychooncology 2009;18:1261-72.

58. Stanton AL, Ganz PA, Kwan L, et al. Outcomes from the Moving Beyond Cancer psychoeducational, randomized, controlled trial with breast cancer patients. J Clin Oncol 2005;23: 6009-18.

59. Miaskowski C, Dodd M, West C, et al. Randomized clinical trial of the effectiveness of a self-care intervention to improve cancer pain management. J Clin Oncol 2004;22:1713-20. 
60. Gustafson DH, Hawkins R, Pingree S, et al. Effect of computer support on younger women with breast cancer. $J$ Gen Intern Med 2001;16:435-45.

61. Wagner-Johnston N. Computer/Online-mediated social support for cancer-related fatigue. I Natl Compr Canc Netw 2013;11:1211-7.

62. Carlson LE, Doll R, Stephen J, et al. Randomized controlled trial of mindfulness-based cancer recovery versus supportive expressive group therapy for distressed survivors of breast cancer (MINDSET). J Clin Oncol 2013;31:3119-26.

63. Cunningham AJ, Edmonds CVI, Jenkins GP, Pollack H, Lockwood GA, Warr D. A randomized controlled trial of the effects of group psychological therapy on survival in women with metastatic breast cancer. Psychooncology 1998;7:508-17.

64. Spiegel D. Mind matters in cancer survival. JAMA 2011;305:502-3.

65. Spiegel D, Bloom JR, Yalom I. Group support for patients with metastatic cancer. A randomized outcome study. Arch Gen Psychiatry 1981;38:527-33.

66. Spiegel D, Bloom JR, Kraemer HC, Gottheil E. Effect of psychosocial treatment on survival of patients with metastatic breast cancer. Lancet 1989;2:888-91.

67. Richardson JL, Shelton DR, Krailo M, Levine AM. The effect of compliance with treatment on survival among patients with hematologic malignancies. J Clin Oncol 1990;8:356-64.

68. Fawzy FI, Canada AL, Fawzy NW. Malignant melanoma: effects of a brief, structured psychiatric intervention on survival and recurrence at 10-year follow-up. Arch Gen Psychiatry 2003;60: $100-3$.

69. Kuchler T, Henne-Bruns D, Rappat S, et al. Impact of psychotherapeutic support on gastrointestinal cancer patients undergoing surgery: survival results of a trial. Hepatogastroenterology 1999;46:322-35.

70. McCorkle R, Strumpf NE, Nuamah IF, et al. A specialized home care intervention improves survival among older post-surgical cancer patients. [see comments]. J Am Geriatr Soc 2000;48:1707-13.

71. Spiegel D, Butler LD, Giese-Davis J, et al. Effects of supportive-expressive group therapy on survival of patients with metastatic breast cancer: a randomized prospective trial. Cancer 2007;110:1130-8.

72. Goodwin PJ, Leszcz M, Ennis M, et al. The effect of group psychosocial support on survival in metastatic breast cancer. $N$ Engl J Med 2001;345:1719-26.

73. Aizer AA, Chen MH, McCarthy EP, et al. Marital status and survival in patients with cancer. J Clin Oncol 2013;31:3869-76.

74. Institute of Medicine. From Cancer Patient to Cancer Survivor: Lost in Transition. Washington, DC: National Academies Press, 2005.

75. Mishra SI, Scherer RW, Geigle PM, et al. Exercise interventions on health-related quality of life for cancer survivors. Cochrane Database Syst Rev 2012;8:CD007566.

76. Craft LL, Vaniterson EH, Helenowski IB, Rademaker AW, Courneya KS. Exercise effects on depressive symptoms in cancer survivors: a systematic review and meta-analysis. Cancer Epidemiol Biomarkers Prev 2012;21:3-19. 